\title{
CERRADO EM ÁREA DISJUNTA EM BREJO DE ALTITUDE NO AGRESTE PERNAMBUCANO, BRASIL
}

\author{
CERRRADO IN DISJOINT AREA IN UPLAND FOREST \\ IN AGRESTE REGION, PERNAMBUCO, BRASIL
CERRADO EN ZONA AISLADA DE BOSQUE HÚMEDO DE ALTITUD
EN EL AGRESTE PERNAMBUCO, BRASIL \\ Linaldo Severino dos Santos - Universidade Federal de Pernambuco - Recife - Pernambuco -Brasil \\ linaldo.geo@gmail.com \\ Helena Paula de Barros Silva - Universidade de Pernambuco - Nazaré da Mata - Pernambuco - Brasil \\ barrosleny@hotmail.com \\ Eugenia Cristina Gonçalves Pereira - Universidade Federal de Pernambuco - Recife - Pernambuco - Brasil \\ eugenia.pereira@pq.cnpq.br
}

\begin{abstract}
Resumo
0 estudo dos brejos de altitude configura-se como fundamental para a Geografia do semiárido pernambucano, uma vez que permite resolver questões de valor tanto na sua vertente física, quanto na social. Nos estudos biogeográficos, a distribuição das espécies do bioma cerrado, em Pernambuco, ainda é pouco referida na literatura. 0 objetivo deste trabalho foi identificar uma possível mancha de cerrado num brejo de altitude entre os municípios de latí e Saloá, no Agreste Meridional de Pernambuco. Para tanto, buscou-se identificar as unidades ambientais existentes na área de estudo e 0 seu padrão climático. Em campo, foram realizadas coletas para a identificação de espécies vegetais e houve o registro fotográfico para a descrição da fisionomia da área de estudo. As espécies de plantas foram coletadas em área de colinas altas, com floresta subcaducifólia sobre Neossolos Quartzarênicos, Argissolos Vermelho-amarelos e Vermelho-escuros, afloramentos de quartzito (5025-25\%), sob clima mesotérmico com chuvas de inverno e com verão quente. Das 13 espécies identificadas, 6 são típicas do bioma cerrado, ocorrendo em áreas de fisionomia arbóreo-arbustiva com altura entre 4 e 6 metros. Assim, pode-se concluir que essa área constitui um núcleo de importância para 0 estudo da biogeografia do bioma em questão, sobretudo no tangente às suas variações ao longo do tempo geológico recente.
\end{abstract}

Palavras-chave: biogeografia, cerrado, brejo de altitude, inventário florístico, Saloá.

\begin{abstract}
Upland Forest studies are very important to understanding geography of semi-arid Pernambuco State because allows to resolve questions about its physical and social themes. The knowledge about species distribution of Cerrado biome in Pernambuco State is little referred in biogeographic literature.The objective of this work is the identification of a cerrado patch inside the upland forest between the municipalities of Saloá and latí. Thus, were identified the geosystems of the study area as well it climate pattern. Further was conducted an floristic inventory and photographic record for plant physiognomy description. The sampling was realized in an environmental unit of steep slopes with semidecidual forest with Arenosols and Ultisols with quartzite rock outcrops in a mesothermal climate with dry and hot summers. From 13 identified species, 6 are common in the cerrado biome, occurring on a tree-shrub plant physiognomy with 4 to $6 \mathrm{~m}$ asl. This allowssaying that Saloá-latí upland Forest is an important nucleus to studies of cerrado biogeography, moreover about its changing belongs the recent geological time.
\end{abstract}

Key words: biogeography, cerrado, upland forest, floristic inventory, Saloá. 


\section{Resumen}

El estudio de los bosques húmedos de altitud, se presentan como fundamental para Geografía del semi árido Pernambuco, ya que estudiar estos bosques permite resolver cuestiones de valor físico (abiótico), como social (biótico). Dentro de los estudios biogeográficos, la distribución de las especies del bioma cerrado en el estado de Pernambuco ha sido poco reportado en la literatura. El objetivo de este estudio fue identificar un posible lugar en un bosques húmedos de altitud entre los municipios de la latí y Saloá en agreste meridional de Pernambuco. Además el estudio busca de identificar las unidades ambientales existentes en el área de estudio, así como su patrón climático. En terreno se recogieron para la identificación de especies de plantas y registro fotográfico para la descripción de la fisonomía de la zona de estudio. Se recogieron las especies de plantas en un área de altas colinas con bosques semideciduos en Neossolos Quartzarênicos, Argissolos Rojo-Amarillo y rojo oscuro, afloramientos de cuarcita (50-25-25\%) bajo el clima mesotermal con lluvias de invierno y de verano caliente. De las 13 especies identificadas, 6 son típicas del bioma cerrado, que se producen en las zonas fisonomía de árboles y arbustos con alturas de entre 4 y $6 \mathrm{~m}$. Esto sugiere que esta área tiene importancia fundamental para el estudio de bioma biogeografía en cuestión, especialmente coincidiendo con sus variaciones en el tiempo geológico reciente.

Palabras clave: biogeografía, cerrado, bosques húmedos de altitud, Saloá, inventario florístico.

\section{Introdução}

O estudo dos brejos de altitude no Nordeste brasileiro, e mais especificamente em Pernambuco, vem se apresentando cada vez de forma mais intensificada nas Ciências Geográficas, Biológicas e também em áreas afins. Contudo, esse estudo não é recente, autores como Gilberto Osório de Andrade (1964), Andrade e Lins (1964), Dárdano de Andrade-Lima (1960) e Vasconcelos Sobrinho (1971), ícones das décadas de 1960 e 1970, já trabalhavam neste tema.

Os trabalhos sobre brejo se mostram de grande importância para a Geografia, pois são verdadeiras áreas de exceção e configuram espaços que oferecem condições naturais mais amenas das condições que o semiárido que os circunda oferece. Esse fato acarreta uma interessante repercussão geográfica, tanto na sua vertente física quanto na social.

Os principais estudos fitogeográficos, nessas áreas de exceção, são direcionados para o levantamento de espécies identificadas como florestas caducifólias ou subcaducifólias, até matas subperenes com espécies perenifólias.

Percebe-se que, nessas áreas de brejos, são poucas as espécies identificadas como pertencentes ao bioma cerrado. São também praticamente inexistentes os trabalhos que se propõem a identificar áreas ou manchas de cerrado em Pernambuco.

Em observação de campo, Costa e Araújo (2007) correlacionaram a existência de uma zona de ecótono entre uma área de depressão no semi- 
árido, com fisionomia de caatinga, e outra de mata em pontos de maior altitude, os brejos; esta zona intermediária possuía um relevo plano a suave ondulado. Isso permitia o acúmulo de partículas de areia, resultante da decomposição mecânica dos afloramentos rochosos, ficando sob a influência de um sistema climático entre o da caatinga e o do brejo. Com isso, a fisionomia resultante não era tão densa como a mata, nem tão esparsa como a caatinga. Dessa forma, um cerrado edáfico pode ser caracterizado em muitos pontos do semiárido nordestino. Entretanto, a devastação dessas áreas deixa-as totalmente descaracterizadas, o que dificulta sobremaneira o seu estudo.

A Fazenda Brejo, em Saloá/PE, por seu alto grau de conservação, foi convertida em Reserva Particular do Patrimônio Natural (RPPN), o que a tornou uma excelente área piloto para testar a hipótese mencionada.

Assim, o objetivo deste trabalho foi investigar, a partir da identificação das principais espécies encontradas, a possível ocorrência de uma mancha de cerrado em brejo de altitude, no Estado de Pernambuco, em razão, sobretudo, da topografia; além disso, estudar outros fatores como os solos e o clima.

\section{Considerações sobre o cerrado}

O termo cerrado faz referência à presença mais ou menos densa de arbustos e árvores, que fecham, ou que, de outra maneira, pode-se dizer que "cerram" o campo (Hatschbach et al., 2005).

As formações vegetais do domínio cerrado sempre interessaram aos botânicos, por serem consideradas um tipo de vegetação peculiar, o que contribuiu para que vários autores conceituassem o cerrado. Sobre isso, Rizzini (1997) afirma:

O cerrado (ou campo cerrado, como também se diz) é a forma brasileira da formação geral chamada savana. Muitas vezes é uma savana arborizada, não poucas é uma savana arbustiva, chegando a ser um simples campo sujo, com apenas arbustos mal desenvolvidos e esparsos por cima do tapete gramináceo. (p. 409)

Não se pode falar sobre o cerrado como um bioma que obedece a padrões uniformes para a totalidade de suas manifestações, pois se trata de um conjunto vegetacional que abrange uma enorme extensão espacial e é o segundo maior bioma brasileiro, ficando atrás somente do bioma 
amazônico. Com essa enorme extensão espacial, verificam-se condições físico-naturais bastante diferenciadas em todo o seu domínio, o que reflete tanto na diversidade de espécies como na estrutura da vegetação, variando de formações basicamente de gramíneas e ervas, no caso do campo limpo, às formações florestais, no caso do cerradão.

0 cerrado em área disjunta

Uma das teorias que encontra mais vazão no meio científico, para explicar a presença de cerrado em outros biomas, é a teoria defendida por autores como Hueck (1957), Ab’Saber (1963), Rizzini (1997), Cole (1986), Carneiro Filho (1993) e Prance (1996) de que a ocorrência do cerrado, em áreas como a Floresta Amazônica, Caatinga, Floresta Atlântica e Floresta de Acicufoliadas no sul do Brasil, deve-se ao fato de que houve um clima mais seco no passado, o que teria favorecido o estabelecimento dessa vegetação nessas áreas (Henriques, 2005).

Essa linha de pensamento é conhecida como Teoria dos Refúgios e Redutos que, de modo geral, trata da distribuição geográfica da fauna e da flora após os eventos climáticos ocorridos no Quaternário. Com isso, de acordo com Oliveira (2005), frentes frias mais intensificadas durante fases glaciais, associadas a mudanças climáticas globais, modelaram a paisagem do atual território brasileiro. Perante essa situação, a vegetação moderna ainda está se equilibrando através dos mecanismos de sucessão vegetal.

Nessa perspectiva, em virtude de uma recessão climática, contingentes de vegetação, antes se apresentando de forma contínua, foram reduzidos a manchas florestais em locais que apresentam condições ecológicas favoráveis ao seu estabelecimento. Esse é o caso dos brejos de altitude presentes no domínio das caatingas do Nordeste brasileiro. Desse modo, as áreas dos brejos nordestinos, muitas vezes denominadas acertadamente de áreas de exceção, constituem verdadeiros exemplos de redutos e refúgios florestais (Ab’Saber, 2006).

Essa configuração fitogeográfica teve origem nas flutuações climáticas do Quaternário, nas quais, em períodos mais úmidos, houve uma expansão da vegetação de maior porte extrapolando os limites de seu domínio de origem. Já em períodos de secura climática, houve o inverso, os ambientes que antes apresentavam uma vegetação de porte florestal 
passaram a desenvolver uma flora de porte arbustivo e herbáceo. É nesse ponto que reside a Teoria dos Refúgios e Redutos Florestais, isto é, regióes que passaram pelo processo de seca climática conseguiram conservar manchas de vegetações úmidas, constituindo áreas de exceção por serem ambientes que oferecem condições conjugando fatores climáticos, pedológicos, altimétricos, dentre outros. Esse é o caso dos brejos de altitude nordestinos que apresentam vegetação distinta da caatinga que os circunda. Como exemplo, podem ser citadas as matas serranas do brejo de Taquaritinga do Norte, no Agreste Pernambucano. A caatinga e o carrasco representam os tipos vegetacionais atualmente característicos da região semiárida; já as manchas de mata úmida, mata estacional, cerrado e cerradão, que ocorrem espalhados pelo semiárido, representam vegetações residuais de períodos climáticos mais úmidos (Fernandes, 1996).

\section{Os brejos de altitude}

Segundo Andrade (1964), o termo brejo serve para designar mais de um fato que se espacializa na natureza, pois mesmo no Nordeste se faz referência a áreas de brejo como regiões alagadiças, ou pantanosas como as encontradas em locais baixos na Zona da Mata pernambucana, como também os brejos-várzeas norte-rio-grandenses do Açu e do Apodi.

Contudo, os brejos que serão tratados aqui são os de altitude, que se configuram como áreas de exceção condicionadas por fatores naturais, caracterizadas como áreas mais amenas que as caatingas que as circundam, onde as vegetações existentes na vertente a barlavento ganham características mais úmidas, variando entre florestas caducifólias ou subcaducifólias, até matas subperenes com espécies perenifólias (Caldas Lins, 1989).

Os termos brejos de altitude e matas serranas, muitas vezes, são tratados como sinônimos, porém há uma diferenciação de conceitos. A Geografia Física estuda o brejo de altitude e a Botânica estuda a mata serrana, posto que o conceito de brejo de altitude abrange o acidente geográfico e suas resultantes como clima, solos, vegetação e fauna; já o conceito de mata serrana é restrito, indica a vegetação resultante do acidente geográfico (Vasconcelos Sobrinho, 1971).

Araújo Filho et al. (2000) caracterizam os brejos de altitude de Pernambuco como regiões úmidas e isoladas dentro de áreas secas, posicionadas a barlavento com desnível relativo médio de 200 metros ou mais. 
Segundo os autores, em Pernambuco, essas regiões situam-se entre 700 e 1.200 metros de altitude.

Acerca do termo brejo, Andrade (1964, p. 24) afirma:

Trata-se, então, de verdadeiros complexos de circunstâncias solidárias, cuja resultante se exprime em termos de exposição. Exposição ao fluxo de massas advectivas de ar úmido, ou a dilatação de massas convectivas nevoentas. Em suma: de posição geográfica em relação às regiões de origem dessas massas e de postura em função da direção geral em que elas anualmente propagam.

Dessa forma, essas áreas úmidas de interface com o semiárido em geral apresentam condições ambientais melhores quanto aos recursos naturais, refletindo na climatologia, pedologia e hidrologia. Por conseguinte, as formas do uso da terra são mais privilegiadas do que as regiões mais próximas do semiárido. Esses ambientes mais amenos mantêm condições naturais que estão intimamente ligadas ao relevo; a altimetria desempenha um importante papel nos mesoclimas de exposição que, segundo Reis (1988), representam uma unidade climática intermediária; os macroclimas representam grandes unidades climáticas regionais e os microclimas ocupam áreas bem mais restritas, como aquelas que podem ser afetadas pelo ser humano.

Material e métodos

A área escolhida para a realização da pesquisa fica situada no Distrito de Iatecá, que pertence ao município de Saloá, Agreste Meridional de Pernambuco, como se observa na Figura1.

\section{Mapeamento das unidades ambientais}

A identificação das unidades ambientais foi realizada a partir da diferenciação de padrões de relevo e sua associação com solos, substrato rochoso e vegetação através de visitas a campo em março e julho de 2009, seguindo recomendações de Cavalcanti et al. (2010).

Os limites das unidades foram determinados a partir da correlação das informações de campo com a base de dados geológica e pedológica disponíveis, que foram sobrepostas às curvas de nível com intervalo de 10 
metros, extraídas de modelo digital de elevação baseado em dados do $\mathrm{Ad}$ vanced Spaceborne Thermal Emissionand Reflection Radiometer (ASTER), com resolução espacial de 30m. Também foi utilizada uma imagem da área (datada de 11 de fevereiro de 2011), obtida pelo Satellite Pourl〉Observation de la Terre (SPOT5), com resolução espacial de 5m, disponível no software Google Earth, em complementação utilizou-se a base de dados dos solos, disponível em Silva et al. (2001).

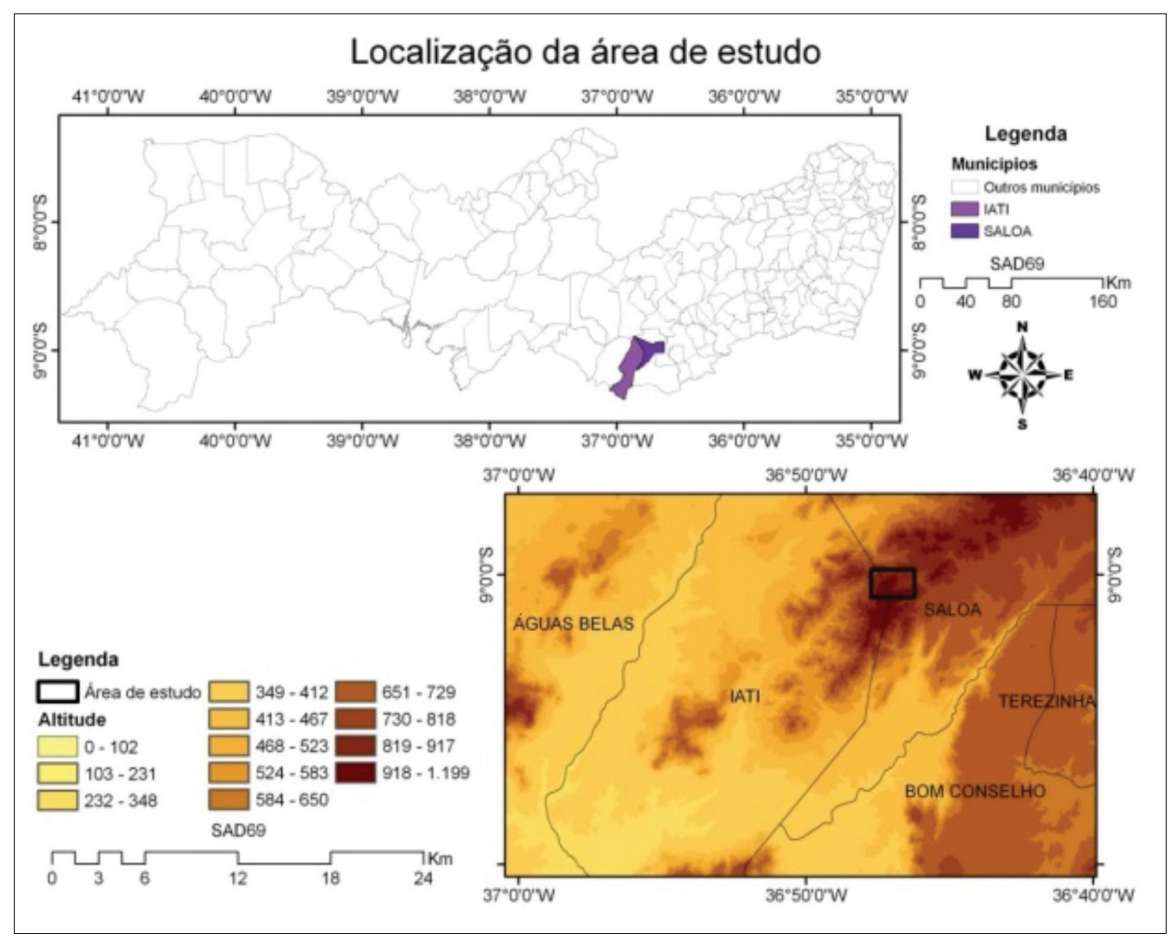

Figura 1 - Mapa de localização e altimetria da área de estudo, município de Saloá/PE, indicando a localização de Pernambuco.

Visitas de campo

Para a fase de coleta de dados em campo, depois de ter sido feita uma análise prévia da área de estudo, foi selecionado um método de fácil aplicação e rapidez na coleta de dados qualitativos, a Avaliação Ecológica Rápida (AER), de acordo com Sobrevilla e Bath (1992). 
Esse método se baseia em uma compreensão prévia da área da pesquisa, com base em bancos de dados, fotografias aéreas, imagens de sensoriamento remoto e mapas para que se possa definir qual será o procedimento adotado em campo.

O trabalho de campo foi realizado em maio de 2009, quando foram feitas as coletas de espécies, seguidas de identificação e deposição em herbário. Para caracterizar corretamente as plantas, foram coletados espécimes que apresentavam flores ou frutos. As espécies foram coletadas sobre Neossolos Quartzarênicos, Argissolos Vermelho-amarelos e Vermelho-escuros, afloramentos de quartzito (50-25-25\%), sob clima mesotérmico com chuvas de inverno e com verão quente. Além disso, fez-se o registro fotográfico para a distinção de fisionomias vegetais, o georreferenciamento dos locais de coleta com uso de receptor GPS.

Em laboratório, esses pontos foram plotados para a visualização 3D do modelo digital de elevação, obtido de dados de radar interferométrico da Shuttle Radar Topography Mission (SRTM), com resolução espacial de 90m. Os mesmos pontos também foram plotados numa imagem orbital do sensor SPOT, de $1^{\circ}$ de dezembro de 2009, obtida gratuitamente pelo programa Google Earth.

\section{Resultados}

\section{Aspectos fisionômicos identificados em topossequência}

A Figura 2 representa o modelo digital de elevação, obtido a partir do perfil topográfico da área de estudo. Quando analisada conjuntamente com a sequência de fotos (Figura 3), pode-se ter uma melhor compreensão da diferenciação dos aspectos fitofisionômicos, em virtude do fator topográfico.

O ponto 1 (Figura 2) e a imagem A (Figura 3) representam um sopé coluvial, composto por material de textura média a argilosa, localizado a uma altitude de $875 \mathrm{~m}$, com árvores espaçadas com altura média de 8 m, e recorrência de espécies exóticas como a Artocarpus heterophyllus (jaqueira), indicando que a área sofreu retirada de vegetação natural. Ao fundo, percebem-se encostas de perfil convexo onde dominam argissolos e cobertura de pastagem com árvores isoladas e pequenos arbustos. 


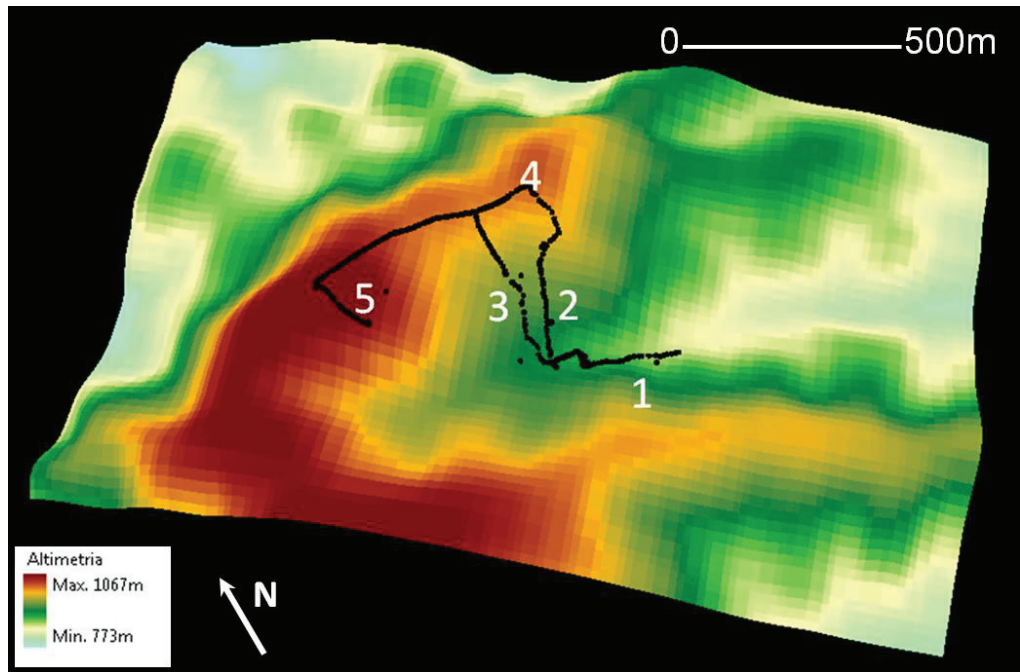

Figura 2 - Modelo Digital do Terreno representando a topossequência da área de Saloá/PE.

Fonte: Elaborado por Linaldo Santos, 2010.
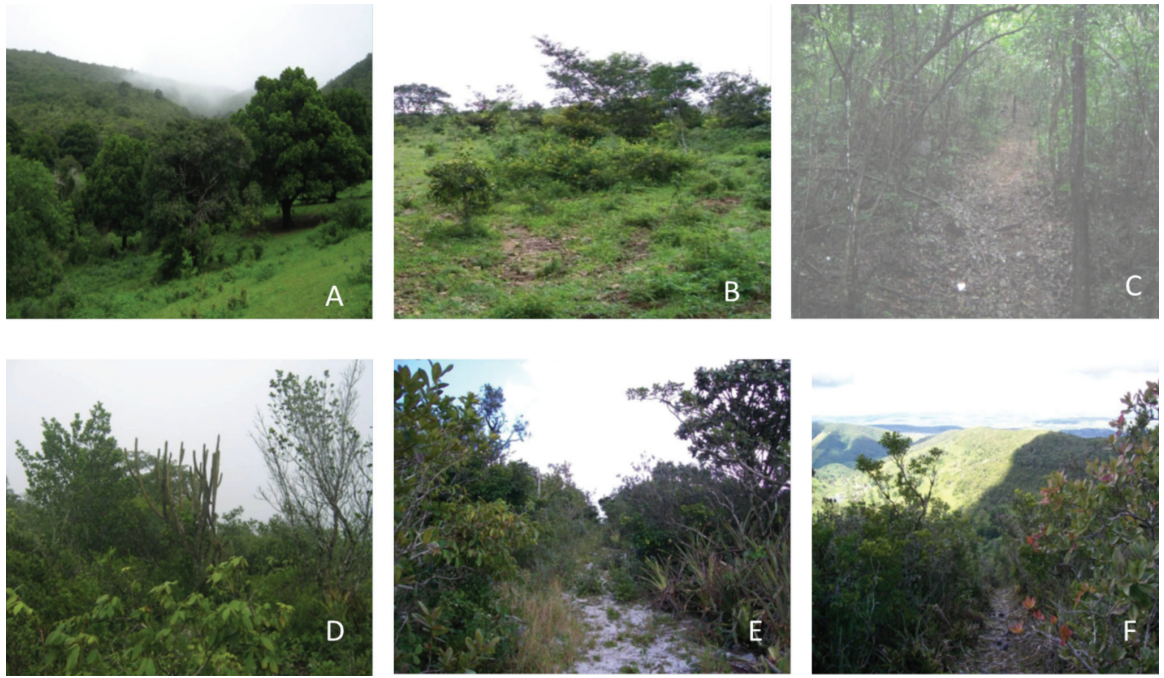

Figura 3 - Sequência de fotos. Legenda: A) Representação da fisionomia do 'ponto 1' , base da encosta; B) 'ponto 2', meia encosta; C) 'ponto 3', meia encosta em área de mata; D) 'ponto 4', borda da mancha de cerrado; E) e F) 'ponto 5', topo da encosta. Fotos: Linaldo Santos, 2009. 
O ponto 2 (Figura 2) e a imagem B (Figura 3) ficam localizados na média encosta, com 955 m de altitude e vegetação em fase de recuperação, apresentando porte herbáceo- arbustivo, com alguns indivíduos atingindo altura máxima de 3m. A comunidade se desenvolve sobre um pavimento detrítico numa encosta de perfil retilíneo.

O ponto 3 (Figura 2) e a imagem C (Figura 3) também se localizam na média encosta e a sua altitude fica em torno dos $950 \mathrm{~m}$, com a vegetação preservada apresentando porte arbóreo, que poderia ser classificada como mata serrana, segundo os critérios de Andrade-Lima (1960).

O ponto 4 (Figura 2) e a imagem D (Figura 3) foram tomados próximo ao topo da encosta. Este setor encontra-se em uma altitude de 1020 $\mathrm{m}$, a vegetação apresenta porte arbóreo-arbustivo, com altura máxima de $5 \mathrm{~m}$, onde foi registrada a ocorrência de espécies de caatinga e cerrado, o que configura uma área ecotonal e representa, dessa forma, a borda da mancha de cerrado.

O ponto 5 (Figura 2) e as imagens E e F (Figura 3) ficam na mesma localidade - o topo da encosta -, com elevação na cota dos 1060 m, similar ao exemplo anterior. Apresenta porte arbóreo-arbustivo, porém os indivíduos apresentam alturas máximas superiores a 5m. Nesse setor, também ocorrem espécies de caatinga e cerrado, apesar de apresentar uma fisionomia mais próxima do cerrado.

\section{Análise das espécies coletadas}

Neste trabalho, foram coletadas, ao longo da encosta e em seu topo, quinze indivíduos de treze espécies mencionadas na literatura consultada. Desse total de espécies, seis delas pertencem ao bioma cerrado; quatro, à caatinga; dois são de restinga; duas espécies são consideradas de carrasco. Vale ressaltar que entre essas espécies há aquelas que são consideradas pertencentes a mais de um ecossistema, o que será tratado mais adiante.

De acordo com as características morfológicas das espécies coletadas, identificaram-se:

$\Rightarrow$ Tilesia baccata (L.) Pruski: Esta é uma espécie da família das Asteraceae, referida na composição florística do cerrado em uma reserva no município de Santa Rita do Passa Quatro, em São Paulo. Batalha e Mantovani (2001) a classificam como componente herbáceo da fitofisionomia 
campo cerrado. Essa espécie está depositada no Herbário Geraldo Mariz (UFP), em exsicata número 59.127.

$\Rightarrow$ Myrcia fallax DC. (Coração-tinto): Mendonça et al. (1997) referem-se à espécie como M. fallax, com hábito arbóreo e características fisionômicas que se enquadram na fitofisionomia de cerrado, popularmente denominada de coração-tinto. O material coletado foi depositado no Herbário UFP sob o número 50.131.

$\Rightarrow$ Coutarea hexandra K.Schum. (Quina-quina): De nome popular quina-quina, a $C$. hexandra pertence à família Rubiaceae e está inclusa no grande grupo de plantas fanerógamas. Mendonça et al. (1997) a classificam como de hábito arbóreo, porém pertencendo à fitofisionomia de mata. O espécime está tombado no Herbário UFP sob o número 59.128.

$\Rightarrow$ Tocoyena formosa K.Schum. (Jenipapo bravo): De nome popular jenipapo bravo, esta espécie pertence à família Rubiaceae. Em trabalho de levantameno florístico na região de Cafuringa, no Distrito Federal, Paula et al. (2009) a enquadraram na fitofisionomia de Cerrado stricto sensu, com hábito arbóreo, o que também é corroborado por Ferri (1979), quando lista as espécies do cerrado do Triângulo Mineiro. O exemplar citado está depositado no Herbário UFP sob o número 59.134.

$\Rightarrow$ Senna macranthera (Collad.) H. S. Irwin \& Barneby. (Fedegoso): Planta arbustiva, pertencente à família Leguminosae (Caesalpiniaceae). Esta espécie é bastante particularizada, segundo Ribeiro, Fonseca e Souza Silva (2001), em trabalho intitulado Cerrado: caracterização e recuperação de matas de galeria, no qual a denominam como de mata de galeria. Em publicação do IBGE, sobre a flora vascular da Reserva Ecológica do IBGE em Brasília, Pereira et al. (1989) também a classificam da mesma forma. Entretanto, Araújo (1998) classifica a S. macranthera como de carrasco. Araújo (1998 apud Figueiredo 1986; 1991) e Fernandes e Bezerra (1990) consideram o carrasco como um tipo particular de vegetação, constituindo espécies de mata, cerrado e caatinga, por serem estabelecidas em ambientes com condições ecológicas diferenciadas das de caatinga, como maior volume pluviométrico e temperaturas mais amenas; também pode ocorrer em cotas altimétricas em torno dos $800 \mathrm{~m}$. Tal indivíduo foi depositado sob o número 59.123.

$\Rightarrow$ Byrsonima gardnerana A. Juss. (Murici pitanga): Esta espécie da família Malpighiaceae possui hábito arbustivo. Com relação à sua clas- 
sificação, B. gardnerana se assemelha com Senna macranthera. Araújo (1998) a denomina como de carrasco; já Bezerra, Lopes e Machado (2009), em trabalho realizado no município de Buíque, no Parque Nacional do Catimbau, embora classifiquem tal espécie como pertencente à caatinga, revelam que parte de seu estudo foi realizado em áreas de cerrado desse parque. Este fato também remete às análises feitas em exsicatas do Herbário Geraldo Mariz (UFP), onde é possível encontrar referência de $B$. gardnerana em áreas de cerrado, em tabuleiros arenosos no município de Goiana. O espécime foi depositado sob o número 59.130.

$\Rightarrow$ Croton tricolor Baill. (Sacatinga): Espécie de hábito arbustivo da família Euphorbiaceae, está tombada no Herbário UFP sob o número 59.132. Em estudo realizado no planalto do Ibiapaba, na Chapada do Araripe, no Estado do Ceará, Araújo (1998) classifica C. tricolor como espécie de carrasco.

$\Rightarrow$ Acritopappus buiquensis D.J.N.Hind \& Bautista: Da família Asteraceae, foi depositado sob o número 59.126. Nascimento (2008), em trabalho sobre a dinâmica vegetacional e climática Holocênica da caatinga, no Parque Nacional do Catimbau, em Pernambuco, classifica essa espécie como um subarbusto do ecossistema caatinga.

$\Rightarrow$ Hypenia salzmannii Mart. ex J.A.Schmid: Espécie da família Lamiaceae (Labiatea), foi depositada sob o número 59.121. Em estudo florístico da caatinga, em Petrolândia/PE, Silva, Araújo e Ferraz (2009) classificam a $H$. salzmannii como um componente herbáceo da caatinga.

$\Rightarrow$ Crotalaria bahiaensis: Espécie pertencente à família Fabaceae, foi depositada sob o número 59.125. Em checklist da flora de Mirandiba/PE, realizado por Córdula, Queiroz e Alves (2008), C. bahiaensis é identificada como parte da flora da caatinga e o arbusto é a sua forma de vida.

$\Rightarrow$ Micristachys híspida (Mart.) Govaerts: De hábito arbustivo, esta espécie pertence à família Euphorbiaceae, depositada sob o número 59.133. De acordo com Santos e Sales (2009), M. híspida apresenta distribuição exclusivamente na América do Sul; ela é encontrada na Argentina, Bolívia, no Brasil e Paraguai. No território brasileiro, distribui-se desde o Pará até Santa Catarina. Em Pernambuco, ocorre sob o domínio da caatinga, em solos arenosos. 
$\Rightarrow$ Myrcia sylvatica DC: A espécie M. sylvatica, depositada sob o número 59.120, ao que tudo indica, é bastante influenciada pelo solo, já que, segundo Sacramento et al. (2007), em estudo realizado sobre as espécies que ocorrem no ecossistema de restinga na Praia do Paiva, município de Cabo de Santo Agostinho/PE, ocorre em Neossolo Quartzarênico, que muito se assemelha ao solo encontrado na área de estudo. A espécie possui hábito arbustivo e pertence à família das Myrtaceae.

$\Rightarrow$ Bomarea edulis Herb.: A espécie, depositada sob o número 59.129, faz parte da família Alstromeriaceae e possui forma biológica de liana. De acordo com Martins et al. (2008), B. edulis pertence ao ecossistema de restinga, baseando-se em estudo sobre o aspecto florístico desse ecossistema no Município de Bertioga/SP.

\section{Considerações sobre o brejo de Saloá e lati}

Em trabalho clássico sobre a fitogeografia de Pernambuco, Lima (1960) estudou os brejos de Garanhuns, Pesqueira, Triunfo, Serra Negra e Tacaratú. O autor, ao comparar as espécies estudadas, verificou que nenhuma delas coincide com as registradas neste trabalho. Esse fato corrobora a hipótese de que a área de estudo seja uma mancha de cerrado edáfico.

Em importante trabalho realizado sobre brejo - Brejos de altitude em Pernambuco e Paraíba: história natural, ecologia e conservação -, na parte referente ao levantamento florístico do Pico do Jabre/PB, Agra, Barbosa e Stevens (2004) relatam que, em um intervalo de sete anos (de 1991 a 1998), foram coletadas 315 espécies pertencentes a 76 famílias; destas, somente três espécies são comuns na área estudada para este trabalho: Senna macranthera (Caesalpiniaceae), coletada por Ribeiro, Fonseca e Souza Silva (2001) em área de cerrado, e por Fernandes e Bezerra (1990) em área de carrasco. Um caso semelhante ocorre com a Byrsonima gardnerana (Malpighiaceae), também classificada como cerrado e carrasco, segundo Bezerra, Lopes e Machado (2009) e Araújo (1998), respectivamente. A outra espécie é a Hypenia salzmannii (Lamiaceae), classificada por Silva, Araújo e Ferraz (2009) como pertencente à caatinga.

Assim, o brejo de Saloá é uma área de exceção entre as áreas de exceção do Agreste Pernambucano, constituindo um núcleo de importân- 
cia para pesquisas sobre a Biogeografia do cerrado, sobretudo em relação às suas variações ao longo do Quaternário recente.

\section{Considerações finais}

Depois de toda a análise e das observações feitas na área de estudo, os resultados apontam a ocorrência de uma mancha de cerrado no brejo de altitude estudado. Esse resultado ganha validação, tendo em vista que, comparando a ocorrência das espécies coletadas no topo do brejo de Saloá com espécies de outros brejos, através da literatura consultada, é possível constatar que há certa diferenciação na composição das espécies encontradas. A própria fisionomia da vegetação está em descompasso com os padrões de entorno, identificados no mapa de geossistemas que, todavia, não apresenta qualquer registro da composição das comunidades vegetais.

Percebe-se que a mancha de vegetação estudada em Saloá se diferencia do conjunto vegetacional dos demais brejos, o que possibilita afirmar que essa área é uma interface entre o úmido e o semiárido e apresenta estreitas relações com o bioma cerrado.

Dessa forma, fatores como a variação do relevo, o solo e o clima influenciam sobremaneira a composição vegetal no brejo de Saloá. Considera-se que a altitude e a exposição à umidade são características essenciais para o estabelecimento de uma mancha de cerrado latu senso no Agreste Pernambucano. Contudo, admite-se que o presente trabalho é um esforço inicial para a identificação de possíveis manchas de cerrado nas áreas de brejo.

\section{Referências}

AB'SABER, A. N. Contribuição à geomorfologia dos cerrados. In: FERRI, M. G. (Org.). Simpósio sobre o cerrado. São Paulo: Ed. USP, 1963. p. 117-124.

. Brasil: paisagens de exceção - o litoral e o Pantanal Mato-Grossense, patrimônios básicos. São Paulo: Ateliê Editorial, 2006.

AGRA, M. F.; BARBOSA, M. R. V.; STEVENS, W. D. Levantamento florístico preliminar do Pico do Jabre, Paraíba, Brasil. In: PÔRTO, K. C.; CABRAL, J. J. P.; TABARELli, M. (Coords.). Brejos de altitude em Pernambuco e Paraíba: história natural, ecologia e conservação. Brasília: MMA; UFPE, 2004. p. 123-138.

ANDRADE, G. O.; LINS, R. C. Introdução ao estudo dos "brejos" pernambucanos. Recife: Universidade do Recife, 1964. 
ANDRADE-LIMA, D. Estudos fitogeográficos de Pernambuco. Recife: Instituto de Pesquisas Agronômicas, v. 5, p. 305-341, 1960.

ARAÚJO FILHO, J. C.; BURGOS, N.; LOPES, O. F.; SILVA, F. H. B.; MEDEIROS, L. A. R.; MÉLO FILHO, H. F. R.; SILVA, F. B. R.; LEITE, A. P.; SANTOS, J. C. P.; SOUSA NETO, N. C.; SILVA, A. B.; LUZ, L. R. Q. P.; LIMA, P. C.; REIS, R.M.G.; BARROS, A. H. C. Levantamento de reconhecimento de baixa e média intensidade dos solos do estado de Pernambuco. Recife: Embrapa Solos, 2000.

ARAÚJO, F. S. Estudos fitogeográficos do carrasco no Nordeste do Brasil. Tese (Doutorado em Biologia Vegetal) - Universidade de Campinas, Campinas, 1998.

BATALHA, M. A; MANTOVANI, W. Floristic composition of the cerrado in the Pé-de-Gigante Reserve (Santa Rita do Passa Quatro, Southeastern Brazil). Acta Botanica Brasilica, n. 15, p. 289-304, 2001.

BEZERRA, E. S; LOPES, A. V; MACHADO, I. V. Biologia reprodutiva de Byrsonima gardnerana A. Juss. (Malpighiaceae) e interações com Abelhas Centris (Centridini) no Nordeste do Brasil. Revista Brasileira de Botânica, n. 32, p. 95-108, 2009.

CALDAS LINS, R. As áreas de exceção do agreste de Pernambuco. Recife: Série Estudos Regionais, SUDENE/PSU/SER, 1989.

CARNEIRO FILHO, A. Cerrados amazônicos: fósseis vivos? Algumas reflexões. Rev. Inst. Geol., n. 14, p. 63-68, 1993.

CAVALCANTI, L. C. S.; SANTOS, L. S.; CORRÊA, A. C. B.; ARAÚJO FILHO, J. C.; Técnicas de campo para descrição de geossistemas: reconhecimento expedito na borda oeste do Maciço Residual de Poço das Trincheiras, Alagoas. Geoambiente online, n. 15, p. 72-102, 2010.

COLE, M. M. The savannas: biogeography and geobotany. London, Academic Press, Harcourt Brace Jovanovich Publishers, 1986.

COSTA, I. R.; ARAÚJO, F. S. Organização comunitária de um encrave de cerrado sensu stricto no bioma caatinga, Chapada do Araripe, Barbalha, Ceará. Acta Botanica Brasilica, v. 21, n. 2, p. 281-291, 2007.

CÓRDUlA, E; QUEIROZ, L. P. de; ALVES, M. Checklist da flora de Mirandiba, Pernambuco: leguminosae. Rodriguésia, Rio de Janeiro, v. 59, n. 3, p. 597-602, 2008.

FERRI, M. G. Ecologia do cerrado. São Paulo: Itatiaia/EDUSP, 1979.

FERNANDES, A. Fitogeografia do semiárido. Reunião Especial da Sociedade Brasileira para o Progresso da Ciência, 4, 1996, Feira de Santana. Anais... Feira de Santana: SBPC, 1996. p. 215-219.

FERNANDES, A.; BEZERRA, P. Estudo fitogeográfico do Brasil. Fortaleza: Stylos Comunicações, 1990.

FIGUEIREDO, M. A. Vegetação. SUDEC (Ed.). Atlas do Ceará, Fortaleza. 1986. p. 24-25.

- A cobertura vegetal do estado do Ceará e as condições ambientais. Tese (Professor Titular) - Universidade Federal do Ceará, Fortaleza. 1991. 
HATSCHBACH, G.; LINSINGEN, L. V.; UHLMANN, A.; CERVI, A. C.; SONEHARA, J. S.; RIBAS, O. S. Levantamento florístico do cerrado (savana) paranaense e vegetação associada. Boletim do Museu Botânico Municipal, Curitiba, n. 66, p. 1-40, 2005.

HENRIQUES, R. P. B. Influência da história, solo e fogo na distribuição e dinâmica das fitofisionomias no bioma cerrado. In: SCARIOT, A.; SOUSA-SILVA, J. C.; FELFILI, J. M. (Orgs.). Cerrado: ecologia, biodiversidade e conservação. Brasília: Ministério do Meio Ambiente, 2005. p. 75-92.

HUECK, K. Sobre a origem dos campos cerrados do Brasil e algumas novas observações no seu limite meridional. Revista Brasileira de Geografia, n. 19, p. 6781, 1957.

MARTINS, S. E.; ROSSI, L.; SAMPAIO, P. S. P.; MAGENTA, M. A. G. Caracterização florística de comunidades vegetais de restinga em Bertioga/SP, Brasil. Acta Botanica Brasilica, São Paulo, v. 22, n. 1, p. 249-274, 2008.

MENDONÇA, R. C de; FELFILI, J. M.; WALTER, B. M. T.; M. C. SILVA JÚNIOR.; REZENDE, A. V.; FILGUEIRAS, T. S.; NOGUEIRA, P. E. Flora vascular do bioma cerrado. Arquivos do Jardim Botânico do Rio de Janeiro, Rio de Janeiro, n. 21, p. 235-392, 1997.

NASCIMENTO, L. R. S. L. Dinâmica vegetacional e climática holocênica da caatinga, na região do Parque Nacional do Catimbau. Dissertação (Mestrado em Geociências) - Universidade Federal de Pernambuco, Recife, 2008.

OLIVEIRA, P. E.; BEHLING, H.; LEDRU, M. P.; BARBERI, M.; BUSH, M.; SALGADOLABOURIAU, M. L.; GARCIA, M. J.; MEDEANIC, S.; BARTH, O. M.; BARROS, M. A.; SCHEEL-YBERT, R. Paleovegetação e paleoclimas do Quaternário do Brasil. In: SOUZA, C. R. G.; SUGUIO, K.; OLIVEIRA, A. M. S.; OLIVEIRA, P. E. (Orgs.). Quaternário do Brasil. Ribeirão Preto: Holos, 2005. p. 52-69.

PAULA, J. E.; IMAÑA-ENCINAS, J.; SANTANA, O. A.; RIBEIRO, G. S.; IMAÑA, C. R. Levantamento florístico e sua distribuição diamétrica da vegetação de um cerrado sensu stricto e de um fragmento de floresta de galeria no Ribeirão Dois Irmãos na APA de Cafuringa. Biotemas, Brasília, p. 35-46, 2009.

PEREIRA, B. A. S.; FURTADO, P. P.; MENDONÇA, R. C.; ROCHA, G. I. Reserva Ecológica do IBGE (Brasília-DF): aspectos históricos e fisiográficos. Boletim FBCN/ Fundação Brasileira para a Conservação da Natureza, Rio de Janeiro, n. 24, p. 30-43, 1989.

PRANCE, G. T. Island in Amazonia: philosophical transactions of the Royal Society of London series B. Biological Sciences, v. 1341, n. 351, p. 823-833, 1996.

REIS, A. C. S. O fator climático. In: MELO, M. L. Áreas de exceção da Paraíba e dos sertões de Pernambuco. Série Estudos Regionais, n. 19, Recife: Ministério do Interior, Superintendência do Desenvolvimento do Nordeste, Diretoria de Planejamento Global, Departamento de Planejamento Sub-Regional e Urbano, Grupo de Desenvolvimento Sub-Regional, 1988.

RIBEIRO, J. F.; FONSECA, C. E. L.; SOUZA SILVA, J. C. Cerrado: caracterização e recuperação de matas de galerias. Planaltina: Embrapa Cerrados, 2001. 
RIZZINI, C. T. Tratado de fitogeografia do Brasil: aspectos ecológicos. São Paulo: Hucitec, 1997.

SACRAMENTO, A. C.; ZICKEL, C. S.; JÚNIOR, E. B. A. Aspectos florísticos da vegetação de restinga no litoral de Pernambuco. Revista Árvore, Viçosa, n. 31, p. 1121-1130, 2007.

SANTOS, V. de J.; SALES, M. F. de. A tribo Hippomaneae A. Juss. ex Spach. (Euphorbiaceae Juss.) no Estado de Pernambuco, Brasil. Acta Botanica Brasilica, Recife, v. 23, n. 4, p. 976-990, 2009.

SILVA, K. A.; ARAÚJO, E. L.; FERRAZ, E. M. N. Estudo florístico do componente herbáceo e relação com solos em áreas de caatinga do Embasamento Cristalino e Bacia Sedimentar, Petrolândia/PE, Brasil. Acta Botanica Brasilica, n. 23, p. 100110, 2009.

SILVA, F. B. R.; SANTOS, J. C. P.; SILVA, A. B.; CAVALCANTI, A. C.; SILVA, F. H. B. B.; BURGOS, N.; PARAHYBA, R. B. V.; OLIVEIRA NETO, M. B.; SOUZA NETO, N. C.; ARAÚJO FILHO, J. C.; LOPES, O. F.; LUZ, L. R. Q. P.; LEITE, A. P.; SOUZA, L. G. M. C.; SILVA, C. P.; VAREJÃO-SILVA, M. A.; BARROS, A. H. C. Zoneamento agroecológico do estado de Pernambuco. Recife: Embrapa Solos, Unidade de Execução de Pesquisa e Desenvolvimento, 2001.

SOBREVILLA, C.; BATH, P. Evaluación ecológica rápida: un manual para usuarios de América Latina y el Caribe. Washington: The Nature Conservancy, 1992.

TABARELLI, M. Brejos de altitude em Pernambuco e Paraíba: história natural, ecologia e conservação. Brasília: Ministério do Meio Ambiente, Universidade Federal de Pernambuco, 2004.

VASCONCELOS SOBRINHO, J. As regiões naturais do Nordeste, o meio e a civilização. Recife: CONDEPE, 1971.

Linaldo Severino dos Santos - Graduado em Geografia pela Universidade Federal de Pernambuco e Mestrando em Geografia pela mesma Universidade.

Helena Paula de Barros Silva - Bacharel e Licenciada em Geografia pela Universidade Federal de Pernambuco, Mestre e Doutora em Tecnologias Energéticas e Nucleares pela mesma Universidade, Professora do Curso de Geografia da Universidade de Pernambuco.

Eugenia Cristina Gonçalves Pereira - Graduada em Geografia pela Universidade Federal de Pernambuco, Mestre em Botânica Criptogâmica pela mesma Universidade, Doutora em Botânica pela Universidade Federal Rural de Pernambuco, Professora titular de Geografia da Universidade Federal de Pernambuco e Bolsista de Produtividade em Pesquisa do CNPq. 